\title{
Oncogenic mutations are associated with histological subtypes but do not have an independent prognostic value in lung adenocarcinoma
}

\author{
This article was published in the following Dove Press journal: \\ OncoTargets and Therapy \\ 13 August 2014 \\ Number of times this article has been viewed
}

\begin{tabular}{|c|}
\hline Haichuan $\mathrm{Hu}^{1,3}$ \\
\hline Yunjian Pan ${ }^{1,3}$ \\
\hline Yuan $\mathrm{Li}^{2,3}$ \\
\hline Lei Wang ${ }^{1,3}$ \\
\hline Rui Wang ${ }^{1,3}$ \\
\hline Yang Zhang ${ }^{1,3}$ \\
\hline Hang $L i^{1,3}$ \\
\hline Ting $Y e^{1,3}$ \\
\hline Yiliang Zhang',3 \\
\hline Xiaoyang Luo ${ }^{1,3}$ \\
\hline Longlong Shao ${ }^{1,3}$ \\
\hline Zhengliang Sun ${ }^{1,3}$ \\
\hline Deng Cai ${ }^{1,3}$ \\
\hline Jie $X u^{1,3}$ \\
\hline Qiong $\mathrm{Lu}^{1,3}$ \\
\hline Youjia Deng ${ }^{1,3}$ \\
\hline Lei Shen ${ }^{2,3}$ \\
\hline Hongbin $\mathrm{Ji}^{4}$ \\
\hline Yihua Sun ${ }^{1,3, *}$ \\
\hline Haiquan Chen ${ }^{1,3, *}$ \\
\hline $\begin{array}{l}\text { 'Department of Thoracic Surgery, }{ }^{2} \text { Department } \\
\text { of Pathology, Fudan University Cancer } \\
\text { Center, Shanghai, People's Republic of China; } \\
{ }^{3} \text { Department of Oncology, Shanghai Medical } \\
\text { College, Fudan University, Shanghai, People's } \\
\text { Republic of China; }{ }^{4} \text { Laboratory of Molecular } \\
\text { Cell Biology, Institute of Biochemistry and } \\
\text { Cell Biology, Shanghai Institute for Biological } \\
\text { Science, Chinese Academy of Science, Shanghai, } \\
\text { People's Republic of China }\end{array}$ \\
\hline $\begin{array}{l}\text { *These authors contributed equally to this } \\
\text { work }\end{array}$ \\
\hline
\end{tabular}

Correspondence: Haiquan Chen;

Yihua Sun

Department of Thoracic Surgery, Fudan University Shanghai Cancer Center, Department of Oncology, Shanghai Medical College, Fudan University,

270 Dong An Road, Shanghai,

People's Republic of China

Tel +86 2I 64430399

Fax +86 21 64430399

Email hqchen I@yahoo.com;

sun_yihua76@hotmail.com
Abstract: Lung adenocarcinomas have diverse genetic and morphological backgrounds and are usually classified according to their distinct oncogenic mutations (or so-called driver mutations) and histological subtypes (the de novo classification proposed by the International Association for the Study of Lung Cancer/American Thoracic Society/European Respiratory Society [IASLC/ ATS/ERS]). Although both these classifications are essential for personalized treatment, their integrated clinical effect remains unclear. Therefore, we analyzed 981 lung adenocarcinomas to detect the potential correlation and combined effect of oncogenic mutations and histological subtype on prognosis. Analysis for oncogenic mutations included the direct sequencing of EGFR, KRAS, HER2, BRAF, PIK3CA, ALK, and RET for oncogenic mutations/rearrangements, and a rereview of the IASLC/ATS/ERS classification was undertaken. Eligible tumors included 13 atypical adenomatous hyperplasia/adenocarcinoma in situ, 20 minimally invasive adenocarcinomas, 901 invasive adenocarcinomas, 44 invasive mucinous adenocarcinomas, and three other variants. The invasive mucinous adenocarcinomas had a lower prevalence of $E G F R$ mutations but a higher prevalence of $K R A S, A L K$, and HER 2 mutations than invasive adenocarcinomas. Smoking, a solid predominant pattern, and a mucinous component were independently associated with fewer $E G F R$ mutations. The $A L K$ rearrangements were more frequently observed in tumors with a minor mucinous component, while the KRAS mutations were more prevalent in smokers. In addition, 503 patients with stage I-IIIA tumors were analyzed for overall survival (OS) and relapse-free survival. The stage and histological pattern were independent predictors of relapse-free survival, and the pathological stage was the only independent predictor for the OS. Although patients with the EGFR mutations had better OS than those without the mutations, no oncogenic mutation was an independent predictor of survival. Oncogenic mutations were associated with the novel IASLC/ATS/ERS classification, which facilitates a morphology-based mutational analysis strategy. The combination of these two classifications might not increase the prognostic ability, but it provides essential information for personalized treatment.

Keywords: oncogenic mutation, IASLC/ATS/ERS classification, personalized treatment, molecular testing, prognosis

\section{Introduction}

Over the past decades, the treatments for lung cancer have progressed with the recognition of interindividual variation, leading to classification according to subtype and histologybased treatment strategies. ${ }^{1-4}$ Lung adenocarcinoma is one of the histological subsets accounting for nearly $40 \%$ of all lung cancer cases. Its treatments have further advanced after the delineation of disease subgroups harboring specific mutant oncogenic kinases, 
such as epidermal growth factor receptor (EGFR), which respond to their corresponding tyrosine kinase inhibitors (TKIs). ${ }^{5-7}$ With the increasing number of the so-called "driver" mutations identified in lung adenocarcinoma, ${ }^{8}$ other prime examples, such as anaphylactic lymphoma kinase (ALK) and its inhibitor crizotinib, continue to emerge and provide patients with molecular-based treatments. ${ }^{9-12}$ Therefore, lung adenocarcinomas could be classified in the genetic dimension by using mutant genes corresponding to the potential targeted molecular therapies. ${ }^{13}$

Recently, a new classification system was proposed by the International Association for the Study of Lung Cancer (IASLC)/American Thoracic Society (ATS)/European Respiratory Society (ERS) to characterize further lung adenocarcinoma in the morphological dimension. ${ }^{14}$ This approach segregates primary lesions considering their invasiveness and predominant histological pattern. Previous studies showed the association of this novel classification system with tumor metabolism, ${ }^{15,16}$ response to radiation, ${ }^{17}$ and prognosis prediction, ${ }^{17-21}$ indicating its role as a supplement to stage-dependent clinical decisionmaking.

To better characterize patients for clinical evaluation and treatment, we sought to evaluate whether these two classification systems correlate with each other and whether the combination of these two dimensions might produce subgroups that are more homogeneous. Several previous studies, all with relatively small sample sizes, reported a possible relationship between the IASLC/ATS/ERS classification and the EGFR and/or the $K R A S$ mutation status. ${ }^{21-25}$ In this study, we comprehensively analyzed 1,015 lung adenocarcinomas for driver mutations by using the IASLC/ATS/ERS classification and incorporated these data with the clinicopathological characteristics to evaluate their mutual correlation and potential role in prognostic prediction.

\section{Materials and methods}

\section{Patients and tissues}

From February 2007-July 2012, surgically resected tumor samples from 1,015 patients with newly diagnosed, pathologically confirmed lung adenocarcinomas were consecutively collected by the Department of Thoracic Surgery at the Fudan University Shanghai Cancer Center. These tumor samples were taken at the time of surgical resection, and the tumor content was at least $20 \%$ evaluated by the pathologist. Among them, 24 patients received neoadjuvant chemotherapy, and ten cases that could not be pathologically/genetically classified were excluded; therefore, 981 completely resected lung adenocarcinomas were assessed for their genetic and morphological classification (Figure S1).

Genomic deoxyribonucleic acid (DNA) or ribonucleic acid (RNA) was extracted from frozen tissues as per standard protocols (RNeasy Mini Kit and QiAamp DNA Mini Kit; Qiagen NV, Venlo, the Netherlands). The total RNA samples were then reverse-transcribed into single-stranded cDNA by using a RevertAid ${ }^{\text {TM }}$ First Strand cDNA Synthesis Kit (Thermo Fisher Scientific, Waltham, MA, USA). Clinical and pathological data, including the age at diagnosis, sex, smoking history, and the pathological tumor, node, metastasis stage, were prospectively collected for analyses. Patients were followed-up in the clinic and/or by telephone for disease recurrence and survival from the date of diagnosis. This research was approved by the institutional review board of the Fudan University Cancer Center, Shanghai, People's Republic of China. All participants provided written informed consent.

\section{Morphological and genetic classification evaluation}

The novel classification of adenocarcinoma was reviewed by two pathologists (Yuan Li and Lei Shen), according to the criteria of the IASLC/ATS/ERS classification as previously described ${ }^{24,25}$ For invasive adenocarcinoma, the predominant pattern was recorded and designated into three pattern groups for survival analysis, as suggested by previous studies: ${ }^{15,17,19,26}$ group 1 refers to lepidic predominant (LEP); group 2 refers to acinar predominant (ACN) or papillary predominant (PAP); and group 3 refers to micropapillary predominant (MP) or solid predominant (SLD) adenocarcinomas. Invasive mucinous adenocarcinoma (IMA) and other variants of invasive adenocarcinoma were analyzed separately, by using the IASLC/ATS/ERS guidelines.

A comprehensive analysis for driver mutations, including the EGFR, KRAS, HER2, BRAF, ALK, RET, and $P I K 3 C A$, was carried out as previously described. ${ }^{13,24,27,28}$ Briefly, EGFR (exons 18-22), HER2 (exons 18-21), KRAS (exons 2-3), BRAF (exons 11-15), and PIK3CA (exons 9-20) were amplified by using the polymerase chain reaction (PCR) with cDNA used for Sanger sequencing. The $A L K$ and RET rearrangements were screened by using PCR and quantitative real-time PCR with $\mathrm{cDNA}^{27,28}$ and confirmed with fluorescence in situ hybridization in formalin-fixed paraffin-embedded specimens. ${ }^{27,28}$

\section{Statistical analyses}

Associations between genetic, morphological, and clinical characteristics were analyzed by using the $\chi^{2}$ test or 
the Fisher's exact test. Patients who were diagnosed with stage I-IIIA lung adenocarcinoma from October 2007-August 2011 were followed-up until June 2012 for relapse-free survival (RFS) and overall survival (OS) analyses (Figure S1). The survival curves were estimated by using the Kaplan-Meier method with differences in survival assessed using the log-rank test. The multivariate survival analysis was conducted using the Cox proportional hazards model. All data were analyzed with SPSS 16.0 (SPSS Inc., Chicago, IL, USA). The two-sided significance level was set at $P<0.05$.

\section{Results}

In total, completely resected tumors from 981 patients with lung adenocarcinoma were eligible for examination and analyses, including 13 preinvasive lesions, 20 minimally invasive adenocarcinomas (MIAs), 901 invasive adenocarcinomas, 44 IMAs, and three colloid/enteric adenocarcinomas. The 901 patients with invasive adenocarcinoma consisted of $71 \mathrm{LEP}, 488 \mathrm{ACN}$, 155 PAP, 24 MP, and 163 SLD subtypes. The patients' characteristics, according to the criteria of the IASLC/ ATS/ERS classification, are shown in Table 1, and the overall mutational spectrum is shown in Figure S2.
(Characteristics of the three colloid/enteric adenocarcinomas are shown in Table S3.)

\section{Driver mutations partially correlate with IASLC/ATS/ERS classification}

The spectrum of driver mutations across the IASLC/ATS/ ERS classifications is illustrated in Figure 1. All driver mutations were mutually exclusive except in 18 patients with coexisting EGFR and PIK3CA mutations, four with both the $K R A S$ and PIK3CA mutations, and one with both the RET and PIK3CA mutations. The overall frequency of the EGFR mutation was $64.7 \%$, much higher than that reported in the Caucasian population, while the overall frequency of the $K R A S$ mutation was $7.1 \%$, much lower than that reported in Caucasian patients. $^{29}$

MIA has a comparable mutation spectrum to invasive adenocarcinoma in terms of the frequency of the $E G F R$ mutants $(P=0.334)$ and pan-negative samples $(P=1.000)$. Surprisingly, the samples from preinvasive lesions (atypical adenomatous hyperplasia [AAH]/adenocarcinoma in situ [AIS]) were found to have a significantly lower $E G F R$ mutation frequency $(P=0.013)$, but higher $H E R 2$ and $B R A F$ mutation frequencies than invasive adenocarcinoma $(P=0.015$ and $P=0.003$, respectively).

Table I Characteristics of patients by IASLC/ATS/ERS classification

\begin{tabular}{|c|c|c|c|c|c|c|c|c|}
\hline & \multirow{3}{*}{$\begin{array}{l}\text { AAH/AIS (\%) } \\
\mathrm{N}=13\end{array}$} & \multirow{3}{*}{$\begin{array}{l}\text { MIA (\%) } \\
\mathbf{N}=20\end{array}$} & \multicolumn{5}{|c|}{ Invasive adenocarcinoma } & \multirow{3}{*}{$\begin{array}{l}\text { IMA (\%) } \\
\mathrm{N}=44\end{array}$} \\
\hline & & & LEP (\%) & ACN (\%) & PAP (\%) & MP (\%) & SLD (\%) & \\
\hline & & & $N=7 \mid$ & $N=488$ & $N=155$ & $\mathbf{N}=\mathbf{2 4}$ & $N=163$ & \\
\hline \multicolumn{9}{|l|}{ Age (years) } \\
\hline$<60$ & 61.5 & 55.0 & 46.5 & 47.3 & 48.4 & 25.0 & 58.9 & 63.6 \\
\hline$\geq 60$ & 38.5 & 45.0 & 53.5 & 52.7 & 51.6 & 75.0 & 41.1 & 36.4 \\
\hline \multicolumn{9}{|l|}{ Sex } \\
\hline Male & 15.4 & 25.0 & 25.4 & 41.0 & 49.0 & 41.7 & 61.3 & 36.4 \\
\hline Female & 84.6 & 75.0 & 74.6 & 59.0 & 51.0 & 58.3 & 38.7 & 63.6 \\
\hline \multicolumn{9}{|l|}{ Smoking } \\
\hline Never & 92.3 & 100.0 & 83.1 & 71.3 & 66.5 & 70.8 & 47.9 & 70.5 \\
\hline Ever & 7.7 & 0.0 & 16.9 & 28.7 & 33.5 & 29.2 & 52.1 & 29.5 \\
\hline \multicolumn{9}{|c|}{ Pathologic stage } \\
\hline IA & 100.0 & 100.0 & 74.6 & 37.7 & 28.4 & 20.8 & 12.9 & 34.1 \\
\hline IB & & & 19.7 & 18.4 & 19.4 & 12.5 & 12.9 & 15.9 \\
\hline IIA & & & 0.0 & 10.0 & 11.0 & 16.7 & 17.8 & 15.9 \\
\hline IIB & & & 0.0 & 1.6 & 6.5 & 8.3 & 3.1 & 6.8 \\
\hline IIIA & & & 4.2 & 25.2 & 28.4 & 41.7 & 44.8 & 25.0 \\
\hline IIIB & & & 0.0 & 2.0 & 0.6 & 0.0 & 4.3 & 0.0 \\
\hline IV & & & $\mathrm{I} .4$ & 4.9 & 5.8 & 0.0 & 4.3 & 2.3 \\
\hline \multicolumn{9}{|c|}{ Pathologic T stage } \\
\hline PTI & 100.0 & 100.0 & 76.1 & 54.1 & 44.5 & 45.8 & 30.1 & 36.4 \\
\hline PT2-T4 & & & 23.9 & 45.9 & 55.5 & 54.2 & 69.9 & 63.6 \\
\hline
\end{tabular}

Abbreviations: IASLC, International Association for the Study of Lung Cancer; ATS, American Thoracic Society; ERS, European Respiratory Society; AAH, atypical adenomatous hyperplasia; AIS, adenocarcinoma in situ; MIA, minimally invasive adenocarcinoma; LEP, lepidic predominant; ACN, acinar predominant; PAP, papillary predominant; MP, micropapillary predominant; SLD, solid predominant; IMA, invasive mucinous adenocarcinoma. 


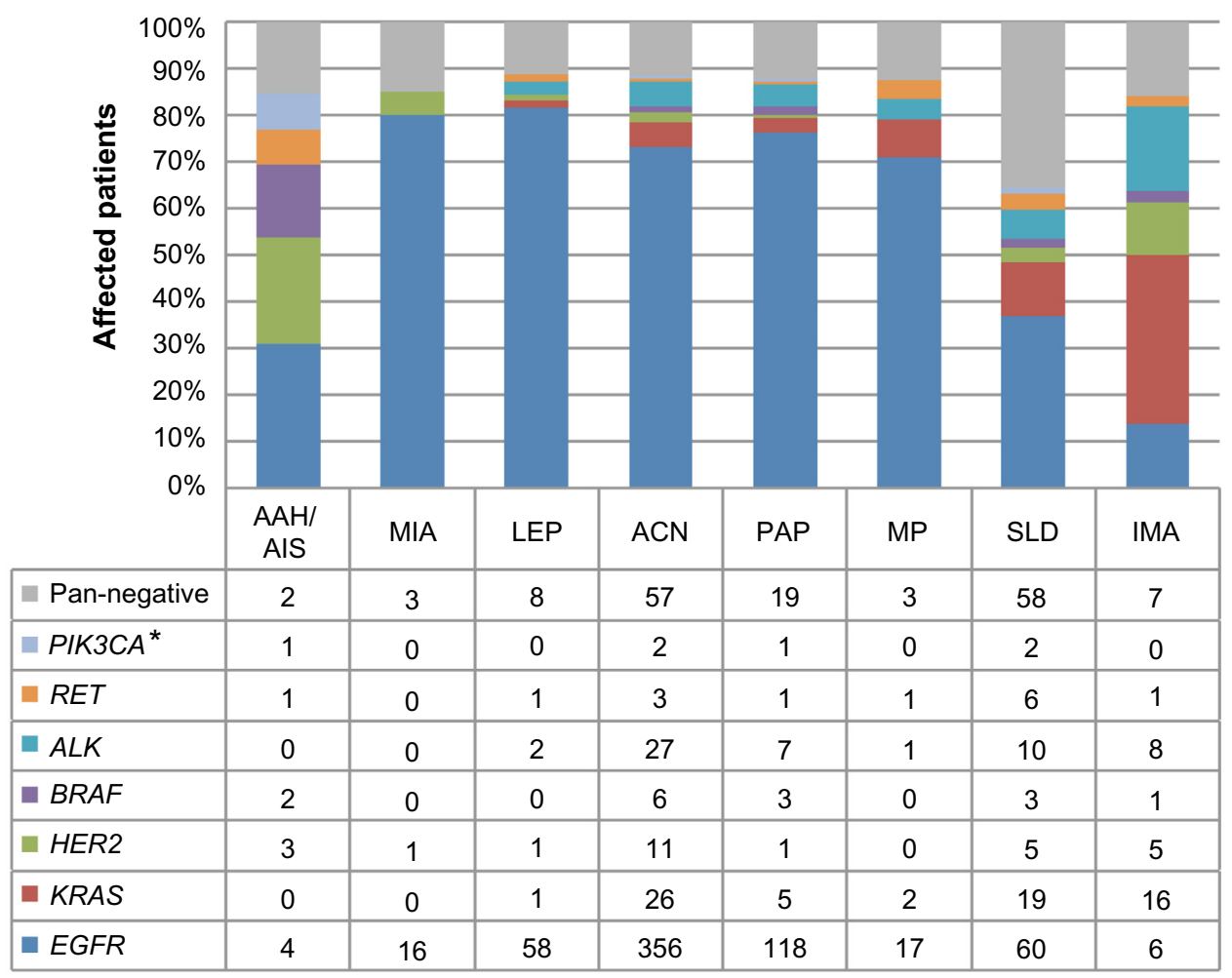

Figure I Driver mutation spectrum, according to the novel IASLC/ATS/ERS classification.

Note: *Indicates samples harboring the PIK3CA mutation without overlap with other driver mutations.

Abbreviations: IASLC, International Association for the Study of Lung Cancer; ATS, American Thoracic Society; ERS, European Respiratory Society; AAH, atypical adenomatous hyperplasia; AIS, adenocarcinoma in situ; MIA, minimally invasive adenocarcinoma; LEP, lepidic predominant; ACN, acinar predominant; PAP, papillary predominant; MP, micropapillary predominant; SLD, solid predominant; IMA, invasive mucinous adenocarcinoma.

Interestingly, IMA was found to have a significantly lower prevalence of $E G F R$ mutations but a higher prevalence of $K R A S, H E R 2$, and $A L K$ mutations than invasive adenocarcinoma $(P<0.001, P<0.001, P=0.003$, and $P=0.003$, respectively). The difference was significant even when compared with MIA ( $P<0.001, P=0.001, P=0.656$, and $P=0.049$, respectively) or LEP invasive adenocarcinoma $(P<0.001$, $P<0.001, P=0.030$, and $P=0.007$, respectively).

For 901 invasive adenocarcinomas, the prevalence of $E G F R$ mutants $(P=0.404)$ and pan-negative samples ( $P=0.995$ ) was relatively equal among the LEP, ACN, PAP, and MP patterns. However, SLD patterns had a significantly lower EGFR mutation frequency $(P<0.001)$ and a higher pan-negative frequency $(P<0.001)$ than non-SLD patterns. Table S1 summarizes the correlation between driver mutations and clinical and pathological characteristics. Univariate analysis revealed a significant association of $K R A S$ mutations with men $(P<0.001)$, smokers $(P<0.001)$, and SLD pattern adenocarcinomas $(P<0.001)$, and the tendency for the $A L K$ fusions was significantly associated with invasive adenocarcinomas with a minor mucinous component $(P<0.001)$. Multivariate analysis (Table S2) confirmed smoking status and SLD pattern as independent factors predicting fewer EGFR mutants and more pan-negative tumors. The pannegative tumors were also independently associated with older age ( $>60$ years), although it was not significant in the univariate analysis, while EGFR mutant tumors were also independently correlated with the absence of a mucinous component. Characteristics of one colloid, two enteric, and four stage III-IV adenocarcinomas with LEP pattern are listed in Table S3.

\section{Mucinous component and smoking status indicate mutational test priority}

Considering the predominant prevalence of EGFR mutations in this Chinese cohort, independent factors, including a minor mucinous component, smoking status, and SLD pattern were used to investigate a practical mutational test strategy in invasive adenocarcinomas. As demonstrated in Figure 2, the frequency of $E G F R$ mutations decreased and that of pannegative tumors increased in smokers and in patients with SLD adenocarcinoma. The KRAS mutations were more common in smokers without a mucinous component, and the $A L K$ mutations were more common in invasive adenocarcinomas 


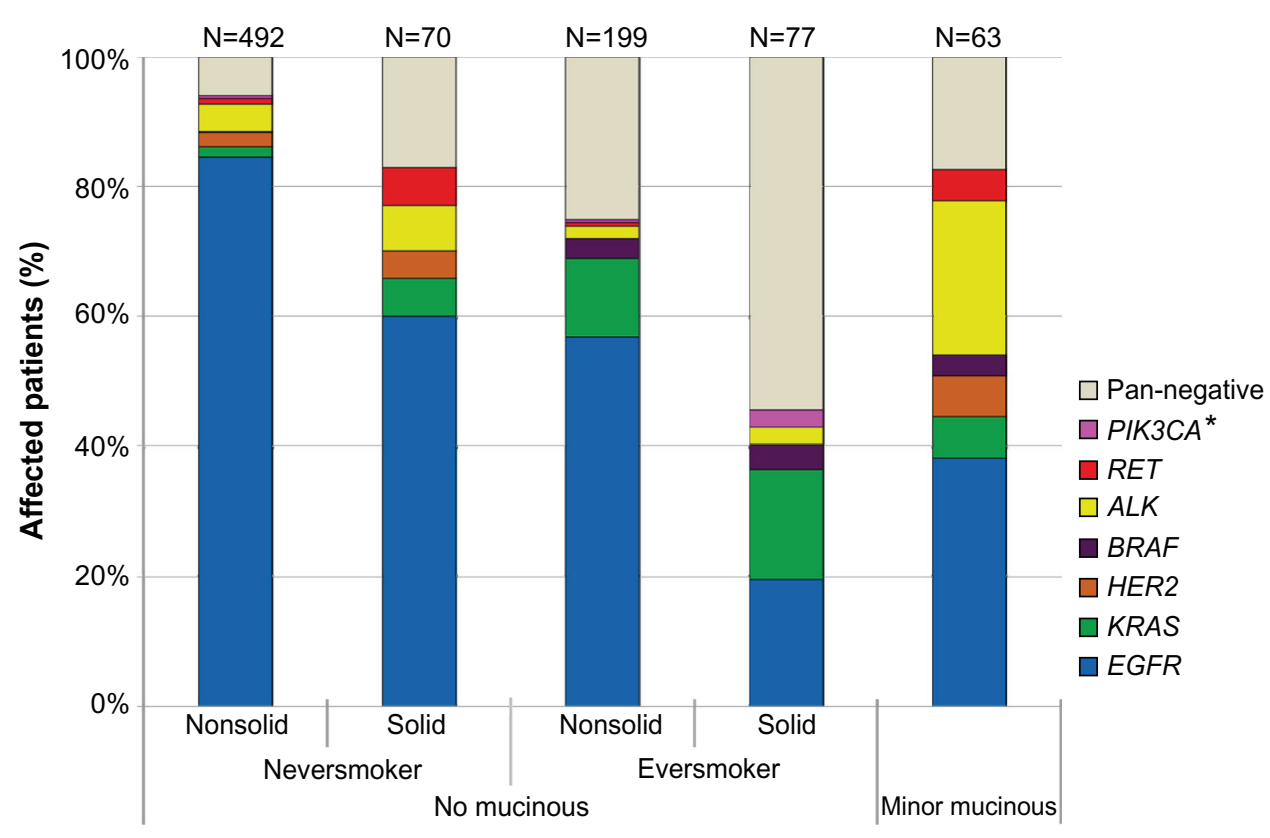

Figure 2 Driver mutation spectrum of 901 invasive adenocarcinomas, according to presence of minor mucinous component, smoking status, and solid predominant pattern. Note: *Indicates samples harboring the PIK3CA mutation without overlap with other driver mutations.

with a minor mucinous component. EGFR remains the major genetic subtype in either subgroup.

\section{Impact of genetic and morphological classifications on prognosis}

The survival data of eight patients with preinvasive lesions or MIAs, 478 patients with stage I-IIIA invasive adenocarcinoma, and 17 patients with stage I-IIIA IMA were collected for RFS and OS analyses. Of these, 277 received adjuvant chemotherapy, with $266(96.0 \%)$ treated with platinum-based doublets and eleven $(4.0 \%)$ with a single regimen. No patient received TKIs as adjuvant chemotherapy. The median follow-up time was 19.0 months.
As listed in Table S4, the sex, smoking status, pathological stage, adjuvant chemotherapy, and histological pattern group were significantly associated with RFS, while the pathological stage, adjuvant chemotherapy, pattern group, and EGFR mutations were significantly associated with OS. As shown in Table 2, the pathological stage and histological pattern group remained the only independent predictors of RFS, and the pathologic stage was the only independent predictor of $\mathrm{OS}$ in the multivariate analysis.

None of the eight patients with preinvasive lesions or MIA had disease recurrence or death during follow-up. Predominant histological pattern and pattern group were significantly associated with RFS $(P<0.001$ and $P<0.001$, respectively) and $\mathrm{OS}(P=0.055$ and $P=0.018$, respectively).

Table 2 Multivariate survival analysis for RFS and OS

\begin{tabular}{|c|c|c|c|c|c|c|c|c|c|c|c|c|}
\hline & \multicolumn{3}{|c|}{ RFS (All, N=478) } & \multicolumn{3}{|c|}{ RFS (EGFR WT, $N=\mid 65)$} & \multicolumn{3}{|c|}{ OS (AII, N=478) } & \multicolumn{3}{|c|}{ OS (EGFR WT, $\mathrm{N}=165)$} \\
\hline & HR & $95 \% \mathrm{Cl}$ & $P$-value & HR & $95 \% \mathrm{Cl}$ & $P$-value & HR & $95 \% \mathrm{Cl}$ & $P$-value & HR & $95 \% \mathrm{Cl}$ & $P$-value \\
\hline Age $(\geq 60$ versus $<60)$ & 1.02 & $0.75-1.40$ & 0.891 & 0.99 & $0.59-1.65$ & 0.956 & 1.47 & $0.91-2.38$ & 0.119 & 1.86 & $0.91-3.77$ & 0.087 \\
\hline $\begin{array}{l}\text { Sex (female versu's } \\
\text { male) }\end{array}$ & 1.00 & $0.62-1.62$ & 0.993 & 0.78 & $0.36-1.69$ & 0.528 & 0.74 & $0.38-1.46$ & 0.389 & 0.68 & $0.26-1.74$ & 0.416 \\
\hline $\begin{array}{l}\text { Smoking (ever versus } \\
\text { never) }\end{array}$ & 1.42 & $0.87-2.32$ & 0.166 & 1.01 & $0.49-2.05$ & 0.988 & 0.87 & $0.44-1.72$ & 0.687 & 0.57 & $0.24-1.37$ & 0.209 \\
\hline Pathologic stage & $\mathrm{I} .47$ & $1.29-1.67$ & $<0.001$ & 1.58 & $1.30-1.91$ & $<0.001$ & 1.39 & $1.13-1.70$ & 0.002 & 1.43 & $1.08-1.91$ & 0.013 \\
\hline Pattern group & $\mathrm{I} .72$ & $1.26-2.33$ & 0.001 & 1.56 & $0.95-2.54$ & 0.077 & 1.22 & $0.76-1.96$ & 0.406 & 1.30 & $0.67-2.54$ & 0.435 \\
\hline $\begin{array}{l}\text { Adjuvant CTX } \\
\text { (with versus without) }\end{array}$ & 0.85 & $0.54-1.33$ & 0.477 & 0.53 & $0.28-0.99$ & 0.048 & I.79 & $0.87-3.68$ & 0.111 & 1.21 & $0.5-2.95$ & 0.668 \\
\hline $\begin{array}{l}\text { EGFR mutation } \\
\text { (MT versus WT) }\end{array}$ & 1.25 & $0.88-1.79$ & 0.209 & - & - & - & 0.67 & $0.40-1.13$ & 0.133 & - & - & - \\
\hline
\end{tabular}

Note: $P$-values less than 0.05 are shown in bold.

Abbreviations: RFS, relapse-free survival; OS, overall survival; HR, hazard ratio; CI, confidence interval; CTX, chemotherapy; MT, mutant; WT, wild type. 
Multivariate analysis confirmed the pattern group as an independent predictor for RFS $(P=0.001)$ but not for OS $(P=0.406)$. The group 1 (LEP) patients had the most favorable outcome, followed by group 2 (CAN and PAP), and by group 3 (SLD and MP) (Figure S3). Patients with IMA had a moderate-to-poor prognosis that could not be differentiated from group 2 or group 3 (Figure S3).

Generally, driver mutations had no impact on RFS $(P=0.290)$ or OS $(P=0.160)$ for invasive adenocarcinoma. However, there was a trend toward a poorer prognosis for patients harboring $H E R 2, B R A F$, or $A L K$ mutations versus those with $E G F R$ mutations, and the difference in OS between patients with EGFR and HER2 or KRAS mutants was statistically significant (Figure S4).

We further investigated whether genetic classification had an impact on survival when it was combined with morphological classification. In the subgroup analysis for patients with stage IIIA tumors (Figure 3), the pattern group 2 (ACN and PAP) tumors harboring $K R A S / H E R 2 / B R A F$ mutations conferred significantly poorer RFS than group 2 and even group 3 (SLD and MP) tumors that did not harbor any KRAS/HER2/ $B R A F$ mutations. However, there was no significant difference between $K R A S / H E R 2 / B R A F$ mutants and the wild-type tumors in group 3 patients. Although the comparison of the OS did not show any statistical significance, a similar trend suggested that the combination of genetic and morphological classification might define a distinct prognostic subgroup.

We also found that in the subcohort of patients harboring a wild-type $E G F R$ gene, the histological pattern group was no longer an independent predictor of RFS, but the adjuvant chemotherapy was (Table 2), suggesting that genetic factors might modify the impact of morphological classification on prognosis.

\section{Discussion}

The diverse responses and/or prognoses of patients reinforce that interindividual variation exists, and that specialized treatment is required. Recurrent kinase mutation analysis provides a genetic approach to scale these variations, according to the patients' potential responses to targeted therapy. The novel IASLC/ATS/ERS classification system provides a morphological predictor of prognosis, and possibly, of therapy response. Therefore, the integration of these two classifications might help to combine both kinds of information, potentially extending our understanding of lung adenocarcinoma. Although detected in several small set studies, the correlation between these two classification systems is still far from clear and their common impact on prognosis remains unknown. To the best of our knowledge, this is the largest scale study that used a comprehensive approach to investigate the correlation between the IASLC/ATS/ERS classification and the driver mutations and to evaluate their combined impact on prognosis.

The distribution of driver mutations partially correlated with the novel IASLC/ATS/ERS classification system. The MIA had a higher EGFR mutation frequency than invasive adenocarcinoma and IMA. For invasive adenocarcinoma, LEP had the largest EGFR mutation frequency followed by
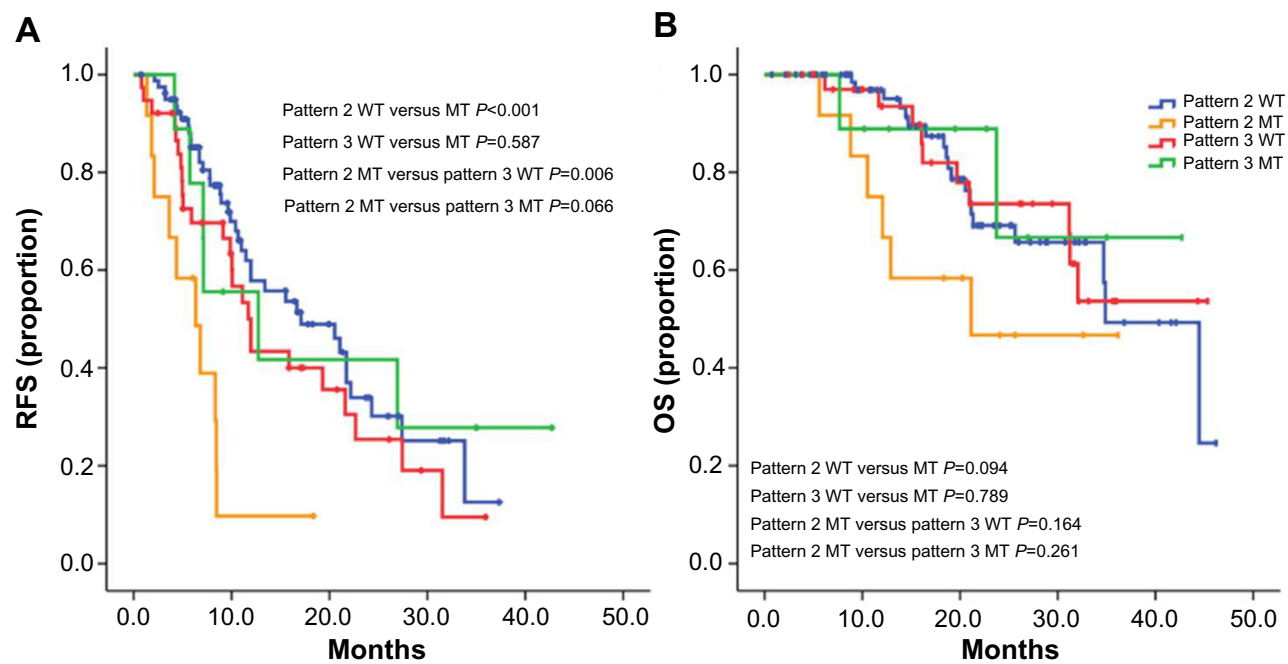

Figure 3 RFS and OS of stage IIIA patients who received adjuvant chemotherapy.

Notes: RFS (A) and OS (B) of stage IIIA patients who received adjuvant chemotherapy. MT, indicative of patients harboring either of HER2, KRAS, or BRAF mutations. WT, indicative of patients harboring wild-type HER2, KRAS, and BRAF genes. Pattern group 2 includes acinar and papillary predominant patterns. Pattern group 3 includes solid and micropapillary predominant patterns.

Abbreviations: RFS, relapse-free survival; OS, overall survival; MT, mutant; WT, wild type. 
PAP, ACN, MP, and SLD. SLD was an independent predictor of KRAS and RET mutations, and the existence of a minor mucinous component was independently associated with a relatively high prevalence of $H E R 2$ and $A L K$ mutations. Either SLD or a mucinous component indicated a reduced chance of harboring a mutant EGFR gene. However, no morphological characteristics could identify a specific genetic subtype, suggesting that genetic heterogeneity remains a morphological scale.

One interesting finding in this study cohort was that preinvasive lesions (AAH/AIS) had a relatively lower EGFR mutation frequency but had a higher frequency of $H E R 2$ and $B R A F$ mutations. This finding greatly differs from the report by Yoshizawa et al, in which more than $80 \%$ of AIS patients harbored an EGFR mutation. ${ }^{21}$ In addition, Sakamoto et al reported that AAH had a higher frequency of KRAS mutation (33\%), which was low in AIS (12\%) and MIA (8\%). ${ }^{30}$ Therefore, the mechanism behind the carcinogenesis driven by the mutant kinases and the pathological pathway underlying this process still warrant further investigation.

One of the great developments of the novel IASLC/ATS/ ERS classification system is the replacement of previous bronchioloalveolar carcinoma with MIA, LEP, and IMA. ${ }^{14}$
Earlier studies showed the association of the bronchioloalveolar carcinoma subtype with EGFR mutations. ${ }^{31}$ Given this novel morphological insight, we found that IMA was associated with fewer $E G F R$ mutations and more $K R A S, H E R 2$, and $A L K$ mutations, indicating a different genetic background in this group of tumors. Survival analysis also revealed a poorer RFS and OS for patients with IMA than for patients with MIA or LEP. These data support the separation of IMA from the old bronchioloalveolar carcinoma classification.

The National Comprehensive Cancer Network guidelines recommend that biomarkers including $E G F R$ and $A L K$ should be initially tested for advanced nonsquamous non-small-cell lung cancer. ${ }^{32}$ While the molecular testing guidelines by the College of American Pathologists, the IASLC, and the Association for Molecular Pathology ${ }^{33}$ suggest that the laboratories may implement testing algorithms to enhance the efficiency of molecular testing of lung adenocarcinomas. When incorporated with the novel IASLC/ATS/ERS classification, we may propose an efficient mutation test algorithm for Chinese or East Asian patients (Figure 4). Patients with AAH/AIS showing a favorable prognosis might not need a mutational test, and patients with MIA should undergo EGFR testing first, owing to its

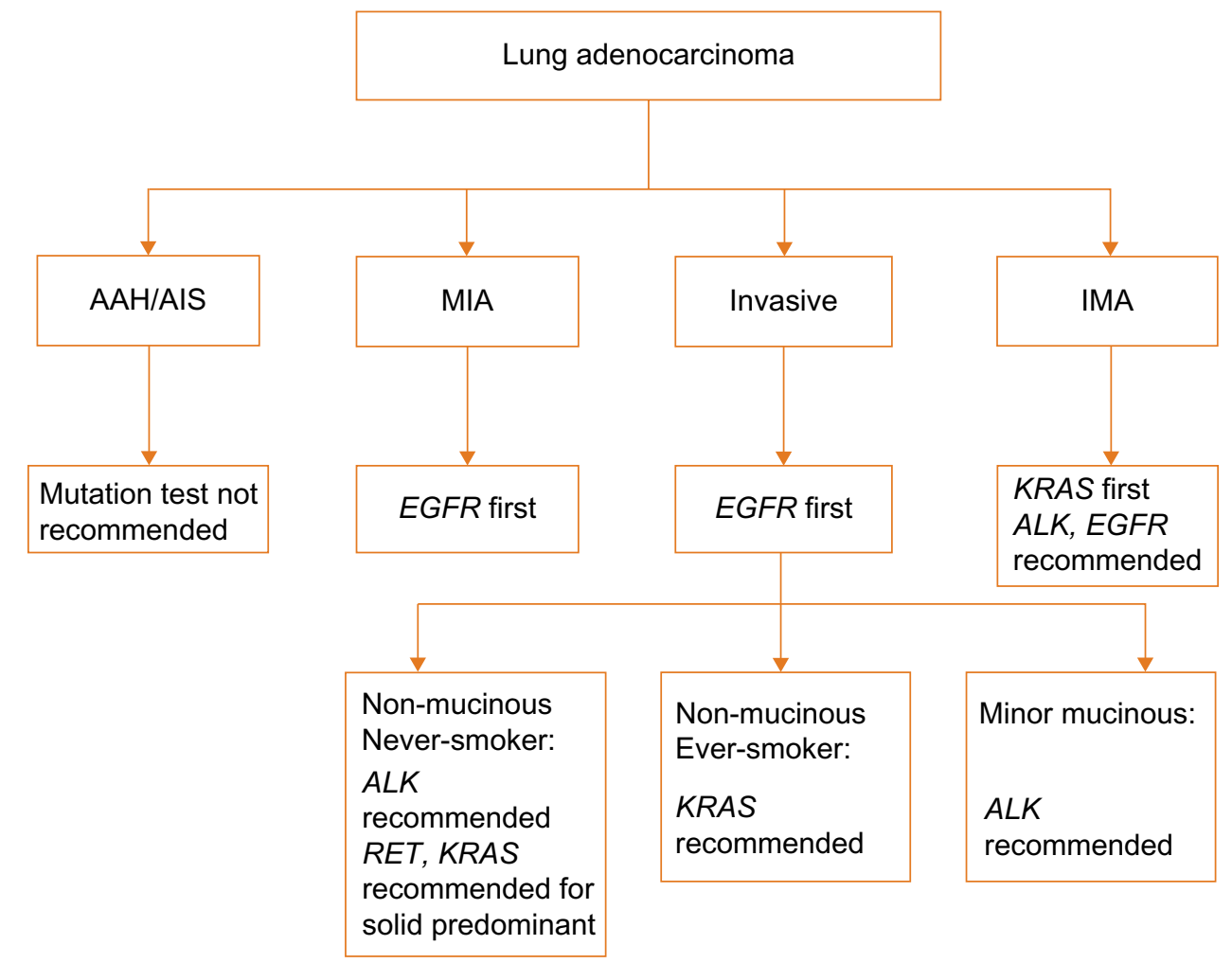

Figure 4 Proposed mutation analysis strategy based on IASLC/ATS/ERS classification.

Abbreviations: IASLC, International Association for the Study of Lung Cancer; ATS, American Thoracic Society; ERS, European Respiratory Society; AAH, atypical adenomatous hyperplasia; AIS, adenocarcinoma in situ; MIA, minimally invasive adenocarcinoma; IMA, invasive mucinous adenocarcinoma. 
predominant prevalence. As a mucinous component and smoking were found to harbor diverse mutation spectrums in invasive adenocarcinoma, tumors with a mucinous component are recommended to receive $A L K$ testing with or after testing for $E G F R$ mutations, and patients who are smokers are recommended to be screened for the KRAS mutations with or after screening for $E G F R$ mutations. IMA had a unique mutation distribution; therefore, this group of patients is recommended to undergo KRAS testing first, followed by $A L K$ and $E G F R$ mutation detection. Given that more and more oncogenes, including $\mathrm{KRAS}^{34}$ and RET, are targetable (ie, cabozantinib), ${ }^{35}$ this testing strategy might not only facilitate laboratory work flow but also the physicians' decision-making on target therapy.

The novel IASLC/ATS/ERS classification is excellent for outcome prediction; patients with preinvasive lesions and MIAs had no recurrence or death during follow-up. For invasive adenocarcinoma, a previous study showed that pattern group was an independent predictor for both diseasefree survival and OS: ${ }^{17}$ however, in this study cohort, we only validated the pattern group as an independent predictor of RFS, but not for OS. Potential reasons for this discrepancy might be the relatively short period of follow-up in our study, and that only patients with stage I-IIIA tumors were included in the survival analysis in our study to achieve more reproducible results in the surgical setting. Genetic classification according to driver mutations generally had no independent impact on the RFS or OS, although a trend toward improved outcomes for EGFR mutant tumors, similar to what was observed in previous studies of resected non-small-cell lung cancers, ${ }^{36}$ was observed.

The addition of morphological classification by using the IASLC/ATS/ERS criteria increased the discriminative ability for predicting outcome; however, patients were still grouped in several specific patterns (eg, ACN and PAP). Therefore, the necessity to identify further patients with different outcomes is questioned. Kadota et al assessed the expression level of thyroid transcription factor-1 by using immunohistochemical staining to identify patients with early disease recurrence in stage I lung adenocarcinomas. ${ }^{18}$ In this study, we found that the KRAS/HER2/BRAF mutations identified a distinct subgroup of patients with stage IIIA tumors who showed early recurrence even after they received adjuvant chemotherapy; therefore, more aggressive perioperative treatment of these patients might be warranted. We also revealed that the histological pattern group was not an independent predictor of survival for the subcohort of patients harboring a wild-type EGFR gene, suggesting that the genetic classification might also supersede morphological classification for prognosis prediction.

Although strengthened by the consecutively collected, completely resected samples as well as the large sample size, several limitations of the current study still need to be noted. First, we only considered the predominant histological pattern in our analysis. However, this might not interfere with the result, as previous studies have sufficiently proved that only the predominant pattern plays a role in survival prediction, ${ }^{17}$ and there might not be intratumoral heterogeneity for mutation analysis in mixed-subtype tumors. ${ }^{23}$ Second, the use of EGFR TKIs, radiation therapy data was not included. Therefore, further investigation into whether the patients with an EGFR mutant gene have different responses to $E G F R$ TKIs of radiation therapy considering their morphological subtype would be of great value.

\section{Conclusion}

This study demonstrated that the novel IASLC/ATS/ERS classification was associated with oncogenic mutations, which further increases our understanding of interindividual variation among lung adenocarcinomas and helps to stratify the mutational analysis strategy in clinical practice. The combination of these two systems provides essential information for specialized treatment, and their combined impact for targeted therapy still requires further investigation. The histological subtype based algorithm is an efficient implement to the CAP/IASLC/AMP molecular testing guideline for East Asian patients.

\section{Acknowledgments}

This work was supported by the funds from: the Key Construction Program of the National 985 Project (985III-YFX0102); the National Natural Science Foundation of the People's Republic of China (81302007, 81172218, 81101761); the Science and Technology Commission of Shanghai Municipality (13ZR1452700, 12XD1402000); Shanghai Municipal Health Bureau Fund (20114206); and grants from the Wu Jieping Medical Foundation.

\section{Disclosure}

The authors report no conflicts of interest in this work.

\section{References}

1. Hansen HH, Selawry OS, Simon R, et al. Combination chemotherapy of advanced lung cancer: a randomized trial. Cancer. 1976;38(6):2201-207.

2. Schiller JH, Harrington D, Belani CP, et al; Eastern Cooperative Oncology Group. Comparison of four chemotherapy regimens for advanced non-small-cell lung cancer. $N$ Engl J Med. 2002;346(2):92-98. 
3. Sandler A, Gray R, Perry MC, et al. Paclitaxel-carboplatin alone or with bevacizumab for non-small-cell lung cancer. $N$ Engl $J$ Med. 2006;355(24):2542-2550.

4. Scagliotti GV, Parikh P, von Pawel J, et al. Phase III study comparing cisplatin plus gemcitabine with cisplatin plus pemetrexed in chemotherapy-naive patients with advanced-stage non-small-cell lung cancer. J Clin Oncol. 2008;26(21):3543-3551.

5. Lynch TJ, Bell DW, Sordella R, et al. Activating mutations in the epidermal growth factor receptor underlying responsiveness of non-small-cell lung cancer to gefitinib. N Engl J Med. 2004;350(21):2129-2139.

6. Paez JG, Jänne PA, Lee JC, et al. EGFR mutations in lung cancer: correlation with clinical response to gefitinib therapy. Science. 2004;304(5676):1497-1500.

7. Pao W, Miller V, Zakowski M, et al. EGF receptor gene mutations are common in lung cancers from "never smokers" and are associated with sensitivity of tumors to gefitinib and erlotinib. Proc Natl Acad Sci U S A. 2004;101(36):13306-13311.

8. Pao W, Hutchinson KE. Chipping away at the lung cancer genome. Nat Med. 2012;18(3):349-351.

9. Butrynski JE, D'Adamo DR, Hornick JL, et al. Crizotinib in ALK-rearranged inflammatory myofibroblastic tumor. $N$ Engl $J$ Med. 2010;363(18):1727-1733.

10. Kwak EL, Bang YJ, Camidge DR, et al. Anaplastic lymphoma kinase inhibition in non-small-cell lung cancer. $N$ Engl $J$ Med 2010;363(18):1693-1703

11. Shaw AT, Yeap BY, Solomon BJ, et al. Effect of crizotinib on overall survival in patients with advanced non-small-cell lung cancer harbouring ALK gene rearrangement: a retrospective analysis. Lancet Oncol. 2011;12(11):1004-1012.

12. Bergethon K, Shaw AT, Ou SH, et al. ROS1 rearrangements define a unique molecular class of lung cancers. J Clin Oncol. 2012;30(8):863-870

13. Sun $Y$, Ren $Y$, Fang Z, et al. Lung adenocarcinoma from East Asian never-smokers is a disease largely defined by targetable oncogenic mutant kinases. J Clin Oncol. 2010;28(30):4616-4620.

14. Travis WD, Brambilla $\mathrm{E}$, Noguchi $\mathrm{M}$, et al. International association for the study of lung cancer/american thoracic society/european respiratory society international multidisciplinary classification of lung adenocarcinoma. J Thorac Oncol. 2011;6(2):244-285.

15. Kadota K, Colovos C, Suzuki K, et al. FDG-PET SUVmax combined with IASLC/ATS/ERS histologic classification improves the prognostic stratification of patients with stage I lung adenocarcinoma. Ann Surg Oncol. 2012;19(11):3598-3605.

16. Chiu $\mathrm{CH}$, Yeh YC, Lin KH, et al. Histological subtypes of lung adenocarcinoma have differential ${ }^{18} \mathrm{~F}$-fluorodeoxyglucose uptakes on the positron emission tomography/computed tomography scan. $J$ Thorac Oncol. 2011;6(10):1697-1703.

17. Warth A, Muley T, Meister M, et al. The novel histologic International Association for the Study of Lung Cancer/American Thoracic Society/European Respiratory Society classification system of lung adenocarcinoma is a stage-independent predictor of survival. $J$ Clin Oncol. 2012;30(13):1438-1446.

18. Kadota K, Nitadori J, Sarkaria IS, et al. Thyroid transcription factor-1 expression is an independent predictor of recurrence and correlates with the IASLC/ATS/ERS histologic classification in patients with stage I lung adenocarcinoma. Cancer. 2013;119(5):931-938.

19. Russell PA, Wainer Z, Wright GM, Daniels M, Conron M, Williams RA. Does lung adenocarcinoma subtype predict patient survival?: A clinicopathologic study based on the new International Association for the Study of Lung Cancer/American Thoracic Society/European Respiratory Society international multidisciplinary lung adenocarcinoma classification. J Thorac Oncol. 2011;6(9):1496-1504.
20. Yoshizawa A, Motoi N, Riely GJ, et al. Impact of proposed IASLC/ ATS/ERS classification of lung adenocarcinoma: prognostic subgroups and implications for further revision of staging based on analysis of 514 stage I cases. Mod Pathol. 2011;24(5):653-664.

21. Yoshizawa A, Sumiyoshi S, Sonobe M, et al. Validation of the IASLC/ATS/ERS lung adenocarcinoma classification for prognosis and association with EGFR and KRAS gene mutations: analysis of 440 Japanese patients. J Thorac Oncol. 2013;8(1):52-61.

22. Shim HS, Lee da H, Park EJ, Kim SH. Histopathologic characteristics of lung adenocarcinomas with epidermal growth factor receptor mutations in the International Association for the Study of Lung Cancer/American Thoracic Society/European Respiratory Society lung adenocarcinoma classification. Arch Pathol Lab Med. 2011;135(10):1329-1334.

23. Sun PL, Seol H, Lee HJ, et al. High incidence of EGFR mutations in Korean men smokers with no intratumoral heterogeneity of lung adenocarcinomas: correlation with histologic subtypes, EGFR/TTF-1 expressions, and clinical features. J Thorac Oncol. 2012;7(2):323-330.

24. Zhang Y, Sun Y, Pan Y, et al. Frequency of driver mutations in lung adenocarcinoma from female never-smokers varies with histologic subtypes and age at diagnosis. Clin Cancer Res. 2012;18(7):1947-1953.

25. Li H, Pan Y, Li Y, et al. Frequency of well-identified oncogenic driver mutations in lung adenocarcinoma of smokers varies with histological subtypes and graduated smoking dose. Lung Cancer. 2013;79(1):8-13.

26. Sica G, Yoshizawa A, Sima CS, et al. A grading system of lung adenocarcinomas based on histologic pattern is predictive of disease recurrence in stage I tumors. Am J Surg Pathol. 2010;34(8):1155-1162.

27. Wang R, Hu H, Pan Y, et al. RET fusions define a unique molecular and clinicopathologic subtype of non-small-cell lung cancer. $J$ Clin Oncol. 2012;30(35):4352-4359.

28. Wang R, Pan Y, Li C, et al. The use of quantitative real-time reverse transcriptase PCR for $5^{\prime}$ and $3^{\prime}$ portions of ALK transcripts to detect ALK rearrangements in lung cancers. Clin Cancer Res. 2012;18(17): 4725-4732.

29. Li T, Kung HJ, Mack PC, Gandara DR. Genotyping and genomic profiling of non-small-cell lung cancer: implications for current and future therapies. J Clin Oncol. 2013;31(8):1039-1049.

30. Sakamoto H, Shimizu J, Horio Y, et al. Disproportionate representation of KRAS gene mutation in atypical adenomatous hyperplasia, but even distribution of EGFR gene mutation from preinvasive to invasive adenocarcinomas. J Pathol. 2007;212(3):287-294.

31. Girard N, Sima CS, Jackman DM, et al. Nomogram to predict the presence of EGFR activating mutation in lung adenocarcinoma. Eur Respir J. 2012;39(2):366-372.

32. National Comprehensive Cancer Network. Non-Small Cell Lung Cancer (Version 3.2014). Available from: http://www.nccn.org/professionals/ physician_gls/pdf/nscl.pdf. Accessed April 10, 2014.

33. Lindeman NI, Cagle PT, Beasley MB, et al. Molecular testing guideline for selection of lung cancer patients for EGFR and ALK tyrosine kinase inhibitors: guideline from the College of American Pathologists, International Association for the Study of Lung Cancer, and Association for Molecular Pathology. J Thorac Oncol. 2013;8(7):823-859.

34. Ostrem JM, Peters U, Sos ML, Wells JA, Shokat KM. K-Ras(G12C) inhibitors allosterically control GTP affinity and effector interactions. Nature. 2013;503(7477):548-551.

35. Drilon A, Wang L, Hasanovic A, et al. Response to Cabozantinib in patients with RET fusion-positive lung adenocarcinomas. Cancer Discov. 2013;3(6):630-635.

36. Kim YT, Seong YW, Jung YJ, et al. The presence of mutations in epidermal growth factor receptor gene is not a prognostic factor for long-term outcome after surgical resection of non-small-cell lung cancer. J Thorac Oncol. 2013;8(2):171-178. 


\section{Supplementary materials}

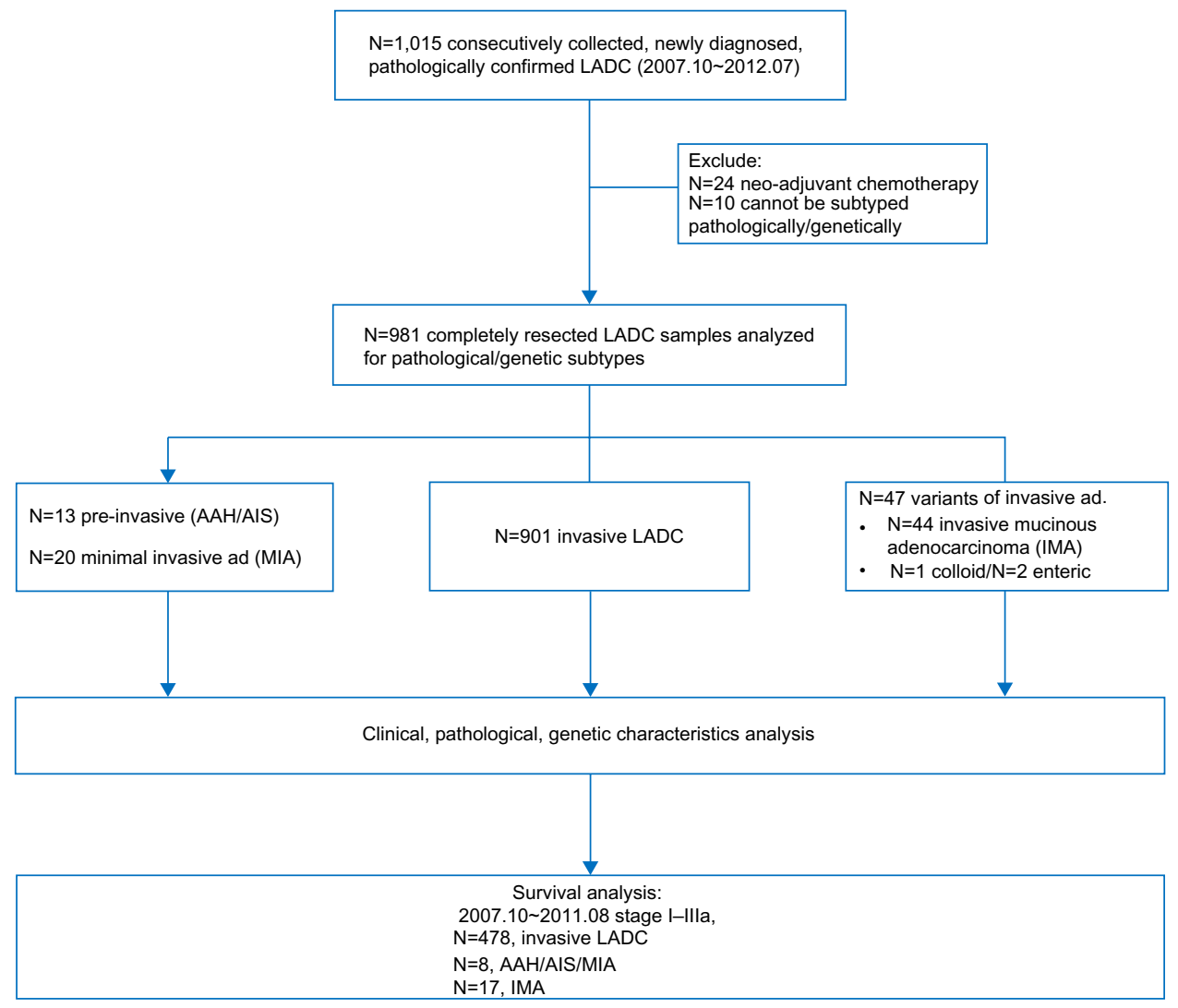

Figure SI Flow chart of the study design.

Abbreviations: LADC, lung adenocarcinoma; AAH, atypical adenomatous hyperplasia; AIS, adenocarcinoma in situ; MIA, minimally invasive adenocarcinoma; IMA, invasive mucinous adenocarcinoma.

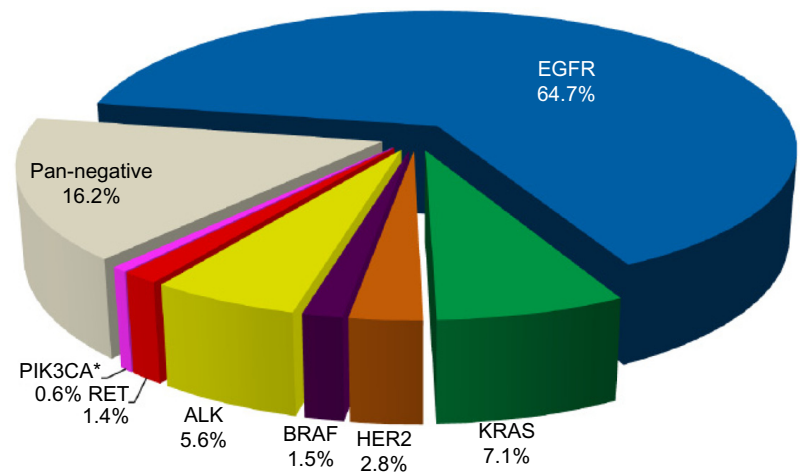

Figure S2 Overall mutation spectrum of $98 \mathrm{I}$ lung adenocarcinomas.

Note: *Indicates samples harboring PIK3CA mutation without overlap with other driver mutations. 

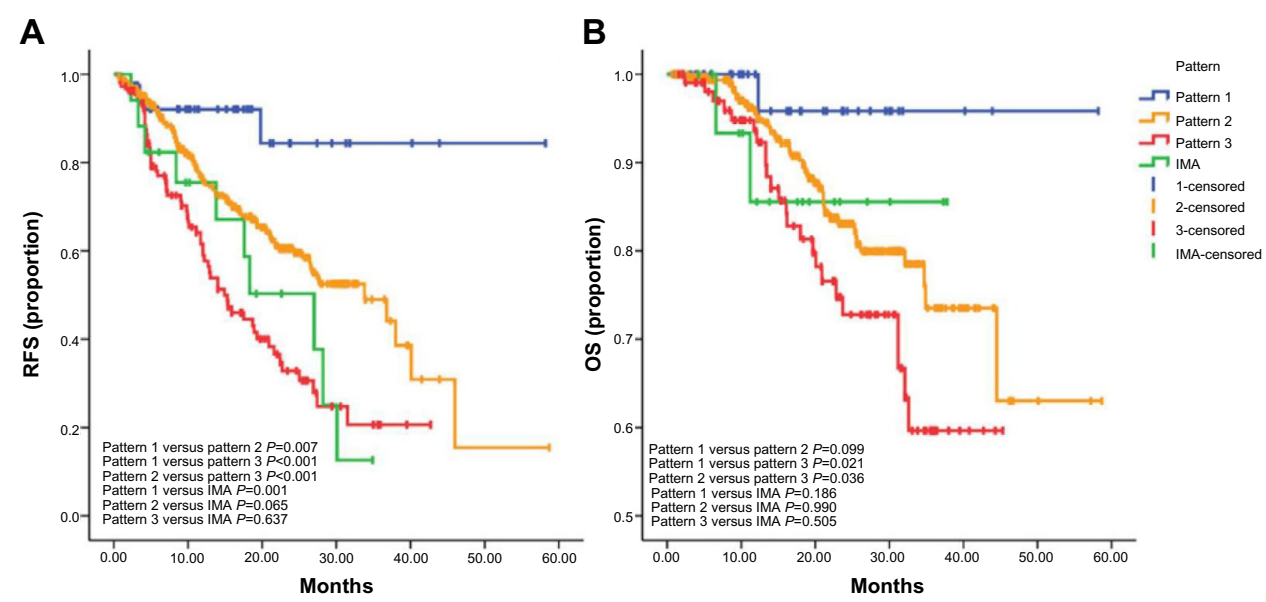

Figure S3 RFS and OS of IA and IMA.

Notes: RFS (A) and OS (B) of 478 IA and I7 IMA. Pattern group I includes LEP predominant pattern. Pattern group 2 includes acinar and PAP patterns. Pattern group 3 includes solid and MP patterns.

Abbreviations: RFS, relapse-free survival; OS, overall survival; IA, invasive adenocarcinomas; IMA, invasive mucinous adenocarcinomas; LEP, lepidic predominant; PAP, papillary predominant; MP, micropapillary predominant.
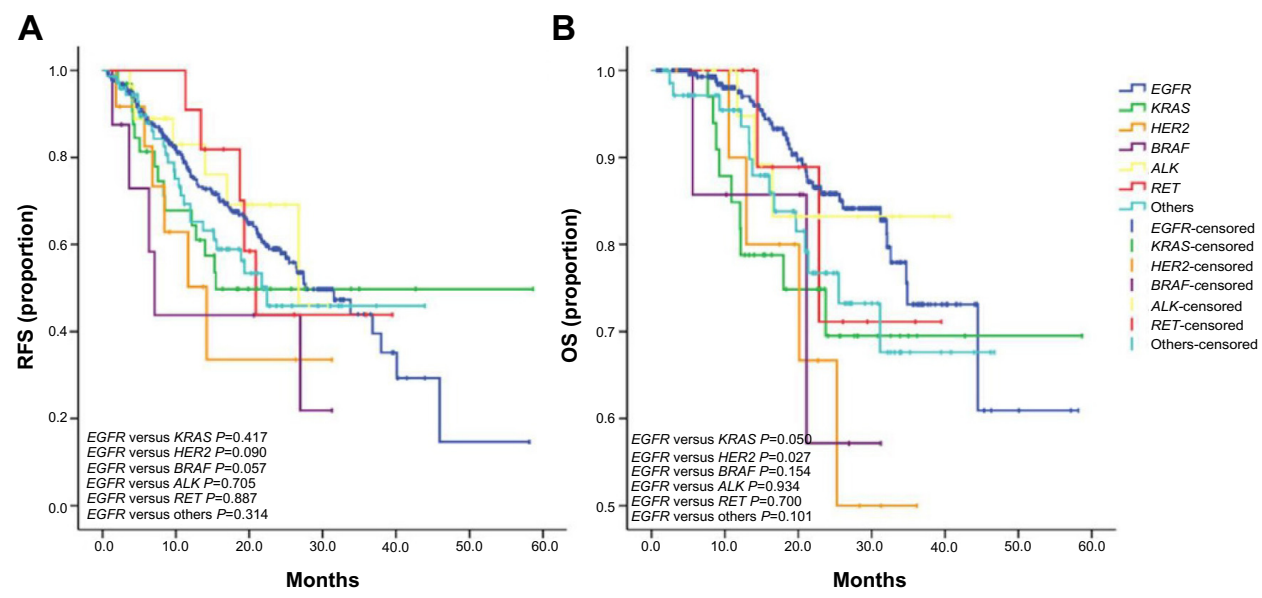

Figure S4 IA by driver mutations.

Notes: RFS (A) and OS (B) of 478 invasive adenocarcinomas by driver mutations.

Abbreviations: IA, invasive adenocarcinomas; RFS, relapse-free survival; OS, overall survival. 


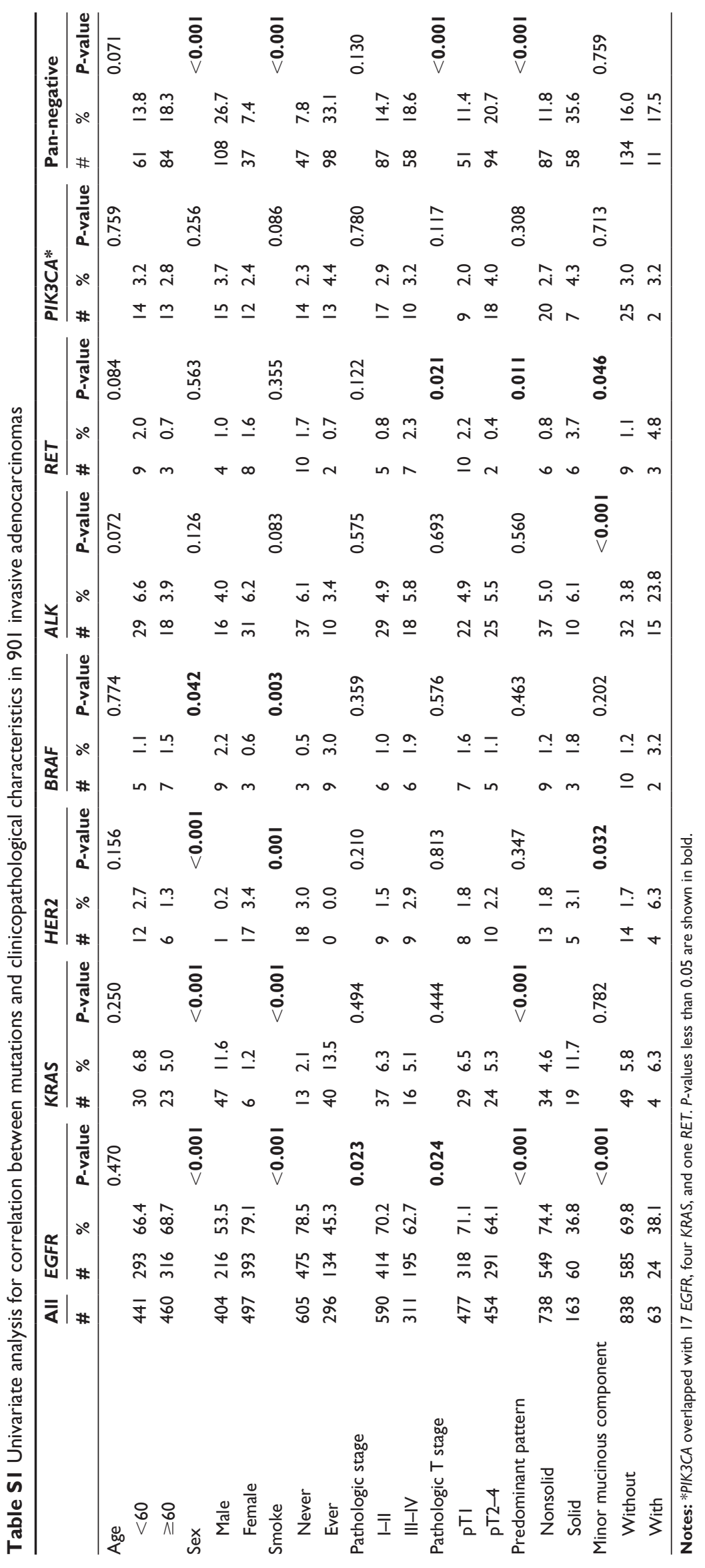


Table S2 Multivariate analysis for correlation with EGFR mutation and pan-negative samples in 90 I invasive adenocarcinomas

\begin{tabular}{|c|c|c|c|c|c|c|}
\hline & \multicolumn{3}{|l|}{ EGFR } & \multicolumn{3}{|c|}{ Pan-negative } \\
\hline & $P$-value & OR & $95 \% \mathrm{Cl}$ & $P$-value & OR & $95 \% \mathrm{Cl}$ \\
\hline Age $(\geq 60$ versus $<60)$ & 0.939 & 1.01 & $0.74-1.39$ & 0.030 & 1.56 & $1.04-2.33$ \\
\hline Sex (female versus male) & 0.266 & 1.31 & $0.8 I-2.1 I$ & 0.396 & 0.75 & $0.39-1.45$ \\
\hline Smoke (ever versus never) & $<0.001$ & 0.30 & $0.18-0.48$ & $<0.001$ & 4.00 & $2.14-7.48$ \\
\hline Pathologic stage (III-IV versus I-II) & 0.876 & 0.97 & $0.69-1.37$ & 0.691 & 0.92 & $0.61-1.39$ \\
\hline Pathologic T stage (pT2-4 versus $\mathrm{pT}$ ) & 0.765 & 1.05 & $0.76-1.46$ & 0.055 & 1.50 & $0.99-2.28$ \\
\hline $\begin{array}{l}\text { Predominant pattern (solid versus } \\
\text { nonsolid) }\end{array}$ & $<0.001$ & 0.24 & $0.16-0.36$ & $<\mathbf{0 . 0 0 1}$ & 3.20 & $2.07-4.93$ \\
\hline $\begin{array}{l}\text { Minor mucinous component (with } \\
\text { versus without) }\end{array}$ & $<0.001$ & 0.22 & $0.12-0.39$ & 0.883 & 1.06 & $0.50-2.23$ \\
\hline
\end{tabular}

Note: $P$-values less than 0.05 are shown in bold.

Abbreviations: $\mathrm{OR}$, odds ratio; $\mathrm{Cl}$, confidence interval.

Table S3 List of three variants of IAs and four stage III-IV LEP adenocarcinomas

\begin{tabular}{|c|c|c|c|c|c|c|c|c|c|c|}
\hline Patient \# & Sex & Age (year) & $\begin{array}{l}\text { Smoking } \\
\text { (pack-year) }\end{array}$ & $\begin{array}{l}\text { Diameter } \\
(\mathrm{cm})\end{array}$ & pT & $\mathbf{p N}$ & pM & Stage & Mutation & $\begin{array}{l}\text { Predominant } \\
\text { pattern }\end{array}$ \\
\hline I & Female & 46 & 0 & 4.0 & $2 a$ & 0 & 0 & IB & Pan-negative & Enteric \\
\hline 2 & Male & 55 & 30 & 3.0 & $2 a$ & 1 & 0 & IIB & Pan-negative & Enteric \\
\hline 3 & Male & 68 & 35 & 3.5 & $2 a$ & 0 & 0 & IB & KRAS & Colloid \\
\hline 4 & Male & 37 & 0 & 4.0 & $2 a$ & 2 & 0 & IIIA & $E G F R$ & Lepidic \\
\hline 5 & Female & 52 & 0 & 2.5 & 4 & 0 & 0 & IIIA & $E G F R$ & Lepidic \\
\hline 6 & Male & 34 & 17 & 1.2 & $2 a$ & 2 & 0 & IIIA & $E G F R$ & Lepidic \\
\hline 7 & Female & 48 & 0 & 1.0 & 4 & 0 & I & IV & $E G F R$ & Lepidic \\
\hline
\end{tabular}

Abbreviations: IAs, invasive adenocarcinomas; LEP, lepidic predominant; pT, pathologic tumor stage; pN, pathologic node stage; pM, pathologic metastasis stage. 
Table S4 Survival analysis for RFS and OS in 487 invasive adenocarcinomas

\begin{tabular}{|c|c|c|c|c|c|c|c|c|c|c|}
\hline & \multicolumn{5}{|l|}{ RFS } & \multicolumn{5}{|l|}{ OS } \\
\hline & $\#$ & Events & $\begin{array}{l}\text { Survival } \\
\text { (months) }\end{array}$ & $95 \% \mathrm{Cl}$ & $P$-value & $\#$ & Events & $\begin{array}{l}\text { Survival } \\
\text { (months) }\end{array}$ & $95 \% \mathrm{Cl}$ & $P$-value \\
\hline Age & & & & & 0.602 & & & & & 0.500 \\
\hline$<60$ & 249 & 93 & 31.5 & $27.3-35.7$ & & 249 & 35 & 45.2 & $39.1-5 \mid .4$ & \\
\hline$\geq 60$ & 229 & 73 & 30.8 & $25.9-35.7$ & & 229 & 34 & 46.9 & $43.5-50.3$ & \\
\hline Sex & & & & & 0.047 & & & & & 0.063 \\
\hline Male & 211 & 90 & 29.6 & $25.2-34.0$ & & 211 & 40 & 43.8 & $37.6-5.0$ & \\
\hline Female & 267 & 76 & 32.1 & $27.1-37.2$ & & 267 & 29 & 48.0 & $44.4-5$ I.5 & \\
\hline Smoking & & & & & 0.007 & & & & & 0.092 \\
\hline Never & 317 & 94 & 31.8 & $27.1-36.4$ & & 317 & 38 & 46.6 & $42.5-5.6$ & \\
\hline Ever & 161 & 72 & 28.2 & $23.2-33.2$ & & 161 & 31 & 46.8 & $43.2-5.4$ & \\
\hline IASLC stage & & & & & $<0.001$ & & & & & $<\mathbf{0 . 0 0 1}$ \\
\hline $\mathrm{IA}$ & 153 & 27 & 40.1 & $33.6-46.5$ & & 153 & 6 & 55.1 & $52.7-57.6$ & \\
\hline IB & 96 & 19 & 30.8 & $26.3-35.2$ & & 96 & 7 & 50.8 & $46.4-55.3$ & \\
\hline$\| \mathrm{A}$ & 53 & 21 & 33.3 & $25.6-41.0$ & & 53 & 10 & 46.1 & $39.3-52.9$ & \\
\hline IIB & 14 & 6 & 20.9 & |3.4-28.4 & & 14 & 2 & 35.4 & $3.3-4.6$ & \\
\hline IIIA & 162 & 93 & 17.7 & I5.2-2.2 & & 162 & 44 & 33.6 & $3.8-36.5$ & \\
\hline Adjuvant CTX, total & & & & & $<0.001$ & & & & & $<0.001$ \\
\hline No & 247 & 53 & 35.8 & $3.5-41.2$ & & 247 & 14 & 53.6 & $51.3-56.0$ & \\
\hline Yes & 231 & 113 & 26.1 & $22.4-29.9$ & & 231 & 55 & 41.4 & $37.3-45.6$ & \\
\hline Adjuvant CTX, stage II-IIIA & & & & & 0.256 & & & & & 0.827 \\
\hline No & 36 & 19 & 14.4 & $11.1-17.6$ & & 36 & 9 & 31.7 & $26.7-36.6$ & \\
\hline Yes & 193 & 101 & 23.9 & 19.9-28.0 & & 193 & 47 & 40.6 & $36.1-45.2$ & \\
\hline Pattern group & & & & & $<\mathbf{0 . 0 0 I}$ & & & & & 0.018 \\
\hline I & 40 & 4 & 50.8 & $43.7-58.0$ & & 40 & I & 56.3 & $52.6-59.9$ & \\
\hline 2 & 330 & 102 & 30.9 & $26.5-35.2$ & & 330 & 44 & 47.3 & $43.5-51.1$ & \\
\hline 3 & 108 & 60 & 19.4 & $16.2-22.6$ & & 108 & 24 & 35.3 & $32.0-38.6$ & \\
\hline Minor mucinous component & & & & & 0.472 & & & & & 0.885 \\
\hline Without & 443 & 155 & 30.4 & $26.6-34.1$ & & 443 & 64 & 47.0 & $43.9-5.1$ & \\
\hline With & 35 & 11 & 26.7 & $21.3-32.1$ & & 35 & 5 & 35.2 & $31.2-39.3$ & \\
\hline Mutations & & & & & 0.353 & & & & & 225 \\
\hline Pan-negative & 73 & 27 & 26.0 & $21.2-3.9$ & & 73 & 14 & 37.3 & $33.1-41.6$ & \\
\hline Mutant & 405 & 139 & 30.7 & $26.9-34.5$ & & 405 & 55 & 46.9 & $43.3-5.5$ & \\
\hline EGFR & & & & & 0.185 & & & & & 0.019 \\
\hline Wild-type & 165 & 65 & 32.8 & $28.2-37.4$ & & 165 & 34 & 45.7 & $41.9-49.5$ & \\
\hline Mutant & 313 & 101 & 29.9 & $25.8-34.0$ & & 313 & 35 & 47.3 & $43.3-51.3$ & \\
\hline KRAS & & & & & 0.529 & & & & & 0.126 \\
\hline Wild-type & 445 & 151 & 29.5 & $25.7-33.4$ & & 445 & 60 & 46.7 & $43.4-49.9$ & \\
\hline Mutant & 33 & 15 & 33.5 & $24.4-42.6$ & & 33 & 9 & 44.8 & $37.2-52.5$ & \\
\hline HER2 & & & & & 0.129 & & & & & 0.081 \\
\hline Wild-type & 466 & 160 & 30.7 & $27.0-34.4$ & & 466 & 65 & 47.1 & $44.0-5.2$ & \\
\hline Mutant & 12 & 6 & 16.5 & $9.1-23.9$ & & 12 & 4 & 27.3 & $2.8-33.9$ & \\
\hline BRAF & & & & & 0.077 & & & & & 0.321 \\
\hline Wild-type & 470 & 161 & 30.8 & $27.1-34.5$ & & 470 & 67 & 46.9 & $43.8-5.0$ & \\
\hline Mutant & 8 & 5 & 15.4 & $6.3-24.5$ & & 8 & 2 & 24.7 & $17.3-32.1$ & \\
\hline ALK & & & & & 0.478 & & & & & 0.699 \\
\hline Wild-type & 451 & 159 & 30.4 & $26.7-34.1$ & & 451 & 66 & 46.7 & $43.5-49.8$ & \\
\hline Mutant & 27 & 7 & 23.5 & 19.2-27.8 & & 27 & 3 & 36.2 & $31.6-4.8$ & \\
\hline RET & & & & & 0.756 & & & & & 0.974 \\
\hline Wild-type & 467 & 161 & 30.4 & $26.7-34.1$ & & 467 & 67 & 46.8 & $43.7-49.9$ & \\
\hline Mutant & 11 & 5 & 27.1 & $19.5-34.6$ & & 11 & 2 & 33.8 & $26.9-4.6$ & \\
\hline PIK $3 C A$ & & & & & 0.438 & & & & & 0.604 \\
\hline Wild-type & 461 & 161 & 30.3 & $26.6-34.0$ & & $46 I$ & 67 & 46.7 & $43.6-49.8$ & \\
\hline Mutant & 17 & 5 & 24.2 & $18.4-29.9$ & & 17 & 2 & 39.8 & $34.1-45.5$ & \\
\hline
\end{tabular}

Note: $P$-values less than 0.05 are shown in bold.

Abbreviations: RFS, relapse-free survival; OS, overall survival; IASLC, International Association for the Study of Lung Cancer; CTX, chemotherapy; CI, confidence interval. 
Table S5 Categories of EGFR mutations

\begin{tabular}{|c|c|c|}
\hline & $\mathbf{n}$ & $\%$ \\
\hline \multicolumn{3}{|l|}{ Sensitizing mutations alone } \\
\hline G7I9X & 9 & $0.9 \%$ \\
\hline G7I9X, deletion & I & $0.1 \%$ \\
\hline G7I9X, L86IQ & 2 & $0.2 \%$ \\
\hline Deletion & 272 & $27.7 \%$ \\
\hline L858R & 278 & $28.3 \%$ \\
\hline L86IQ & 7 & $0.7 \%$ \\
\hline \multicolumn{3}{|l|}{ Resistance mutations } \\
\hline S768I & 2 & $0.2 \%$ \\
\hline S768I, exon 20 other (insertion) & 4 & $0.4 \%$ \\
\hline Exon 20 other (insertion) & 31 & $3.2 \%$ \\
\hline \multicolumn{3}{|c|}{ Combination of sensitizing and resistance mutations } \\
\hline G7I9X, T790M & I & $0.1 \%$ \\
\hline G7I9X, S768I & 5 & $0.5 \%$ \\
\hline Deletion, T790M & 4 & $0.4 \%$ \\
\hline Deletion, exon 20 other (insertion) & I & $0.1 \%$ \\
\hline T790M, L858R & 5 & $0.5 \%$ \\
\hline S768I, L858R & 4 & $0.4 \%$ \\
\hline L858R, exon 20 other (insertion) & 3 & $0.3 \%$ \\
\hline L86IQ, exon 20 other (insertion) & I & $0.1 \%$ \\
\hline \multicolumn{3}{|l|}{ Others } \\
\hline E709_T7I0>D & 4 & $0.4 \%$ \\
\hline Exon 19 insertion & I & $0.1 \%$ \\
\hline Negative & 346 & $35.3 \%$ \\
\hline
\end{tabular}

OncoTargets and Therapy

\section{Publish your work in this journal}

OncoTargets and Therapy is an international, peer-reviewed, open access journal focusing on the pathological basis of all cancers, potential targets for therapy and treatment protocols employed to improve the management of cancer patients. The journal also focuses on the impact of management programs and new therapeutic agents and protocols on

\section{Dovepress}

patient perspectives such as quality of life, adherence and satisfaction. The manuscript management system is completely online and includes a very quick and fair peer-review system, which is all easy to use. Visit http://www.dovepress.com/testimonials.php to read real quotes from published authors.

\footnotetext{
Submit your manuscript here: http://www.dovepress.com/oncotargets-and-therapy-journal
} 